\title{
Multi-terrain Quadrupedal-wheeled Robot Mechanism: Design, Modeling, and Analysis
}

\author{
Eric Gratton, Mbadiwe Benyeogor, Kosisochukwu Nnoli, Oladayo Olakanmi, Liam Wolf, \\ Zavier Berti, Sushant Kumar, and Piyal Saha
}

\begin{abstract}
For a robot to navigate in terrains of rough and uneven topographies, its drives and controllers must generate and control large mechanical power with great precision. This paper is aimed at developing an autonomous robot with activesuspensions in form of a hybrid quadrupedal-wheel drive mechanism. This involves a computational approach to optimizing the development cost without compromising the system's performance. Using the Solidworks CAD tool, auxiliary components were designed and integrated with the bed structure to form an actively suspended robot drive mechanism. Also, using the S-Math Computing tool, the robot's suspension system was optimized, employing a four-bar mechanism. To enhance the compatibility of this design with the intended controller, some mathematical equations and numerical validations were formulated and solved. These included the modeling of tip-over stability and skid steering, the trendline equations for computing the angular positions of the suspension servomotors, and the computation of $\mathrm{R}^{2}$ - values for determining the accuracy of these trendline equations. Using finite element analysis (FEA), we simulated the structural integrity of key subcomponents of the final structure. The results show that our mechanical design is appropriate for developing an actively suspended robot that can efficiently navigate in different terrestrial sites and topographies.
\end{abstract}

Index Terms - Active suspension, Four-bar mechanism, Servo- motor, Skid steering, Tip-over stability, Quadrupedalwheelrobot.

\section{INTRODUCTION}

Multi-Terrain robots are mobile robotic systems with an enhanced drive mechanism and control system, for navigation in rough topographies [1]. A notable feature of this mechanism is the active-suspension, which usually takes the form of a leg-wheel mechanism [2]. Consequently, the choice of steering mechanism and control strategies are influenced. Several steering mechanisms have been adapted to different designs of an actively suspended robot. A typical example is a skid-steering system, which is popular among roboticists due to its simplicity, in terms of structure and control model [3]. In the present paper, we propose a robot mechanical system with active-suspensions in the form of a hybrid quadrupedal-wheel drive mechanism. We incorporated the

Published on December 10, 2020.

E. Gratton, Automata Research Group (ARG), Arvin Instruments Nigeria Ltd., Ibadan, Nigeria.

(e-mail: ericjjgratton@ ${ }^{@ m a i l . c o m) . ~}$

M. Benyeogor, Automata Research Group (ARG), Arvin Instruments Nigeria Ltd., Ibadan, Nigeria.

(e-mail: samrexbenzil@ gmail.com).

K. Nnoli, Automata Research Group (ARG), Arvin Instruments Nigeria Ltd., Ibadan, Nigeria.

(e-mail: kosynnoli@gmail.com).

O. Olakanmi, Dept. of Electrical and Electronic Engineering, University of Ibadan, Ibadan, Nigeria.

(e-mail: olakanmi.oladayo@ui.edu.ng). skid-steering system into the control model of the robot. A major consideration is the design of mechanical components, to ensure that they are optimal and cost-effective. This includes the structural integrity of these components, based on their geometry and material properties, and the cost of fabrication. Weused finite element analysis (FEA) to simulate the structural integrity of these components to determine their susceptibility to failure.

This project is the first phase of a bottom-up plan to developing a ruggedized autonomous robotic system for navigating different rough terrains. This includes the design (i.e., mechanism and control), manufacturing, and fieldtesting. In the present paper, we aim to design the mechanical structures and 3D models of this robot, as an actively suspended 4-legged wheeled vehicle. Thus, our project is a work in progress.

\section{RELATED WORKS}

The quest to develop autonomous vehicular systems that could navigate in rough topographies has reshaped the science of wheeled mobile robots (WMR) and plotted a new direction for applications in terrestrial remote sensing and space exploration. A current trend is to develop WMR that have active suspensions to ease their adaptability for off-road navigation. This is because the WMR is normally not meant to navigate on paved roads during its operation, and therefore, requires a drive system that is suitable for multiple terrains. This need has attracted many mechanical engineers to mobile robotics, which consequently has seen much creativity in the design of drive systems. Recent developments in this area include the work of Sun et al., which involves the design of a quadrupedal wheel drive based on the concept of eccentric paddle mechanism, for high mobility [1]. Also, Gonzalez et al. used the principle of four-bar mechanism to design a suspension system that guides wheels in climbing structured obstacles and steps [4]. According to them, this could enhance the climbing ability of WMR and robotic wheelchairs. Some example of active-suspension-based WMR are the leg-wheel hybrid designs of Ottaviano and Hirose, which describes a quadrupedal driving mechanism in [5], [6].

L. Wolf, Dept. of Mechanical Engineering, University of Alberta, Edmonton, Canada.

(e-mail: 1wolf@ualberta.ca).

Z. Berti, Dept. of Mechanical Engineering, University of Alberta, Edmonton, Canada.

(e-mail: zberti@ualberta.ca).

S. Kumar, Dept. of Physics and Electrical Engineering, University of Bremen, Bremen, Germany.

(e-mail: sushant ${ }^{\circledR}$ uni-bremen.de).

P. Saha, Dept. of Physics and Electrical Engineering, University of Bremen, Bremen, Germany.

(e-mail: piyal@uni-bremen.de). 
A requirement for robotic maneuvering in the 2-D plane is an active-suspension system that enables the high steerability of the robot. Many existing 4-wheel robots possess the Ackermann steering systems like that of Olakanmi in [7], which requires complicated mechanical linkages and can limit steering efficiency. To reduce these complications, many roboticists adopt the skid-steering system, which does not require the actual mechanical twisting of wheels to perform steering action [8]. According to Mokhiamar et al., the adoption of skid steering eliminates the mechanical interdependency of the wheels, through the direct motorization of each wheel. Consequently, this delegates more control of the wheels to the controller [8].

This paper builds upon the concepts in the abovementioned pieces of literature from an engineering standpoint. For active suspension, we have developed a design similar to that of [5], [4], [9]. To improve on these, we incorporated servomotors in our suspension system. Unlike that of Jiang et al. [9], which is a linear-motor actuated rocker-and-balance mechanism, ours is an electronically controlled servomechanism that has higher precision in the control of the pitch and roll motion of the robot, during navigation. For steering, we drew insights from [3], [8], to formulate a skid-steering control model for our robot. Generally, our emphasis is on a design that is optimal, practical, and cost-effective. Unlike many existing works, our study also covers the characterization of the selected fabrication materials by FEA simulation.

\section{MATERIALS AND METHOD}

This section describes our aim to develop a robotic quadrupedal-wheeled drive system. This development includes the design of the rigid components, kinematic analyses, dynamical models, and the simulation of selected structures. Fig. 1 shows the 3-D model and design of our robotic system. This describes only its mechanism and actuators. The design incorporates eight actuators. These include four servomotors (for active suspension) and four geared dc-motors (for mobility). The remaining parts of this literature discuss the working and operation of this system.

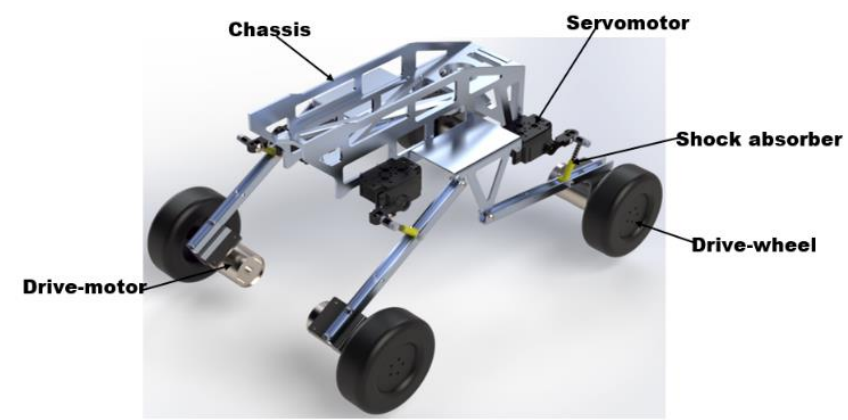

Fig. 1. 3-D model of the quadrupedal-wheeled robot mechanism.

\section{A. Chassis Design and Fabrication}

Our work introduces unique challenges in terms of mechanical design. To start, the chassis was recycled from a dismantled humanoid robot system. Using this recycled material has economic benefits but causes issues when it comes to the placement and the dynamics of the suspension.
The chassis has pre-designated articular holes, which means the choice of point locations on the chassis for attaching the suspension system is limited. The shape of the chassis is also not symmetric from front to back, which requires the front and rear suspension to have different dynamics. The 3-D model of the adopted chassis is shown in Fig. 2.

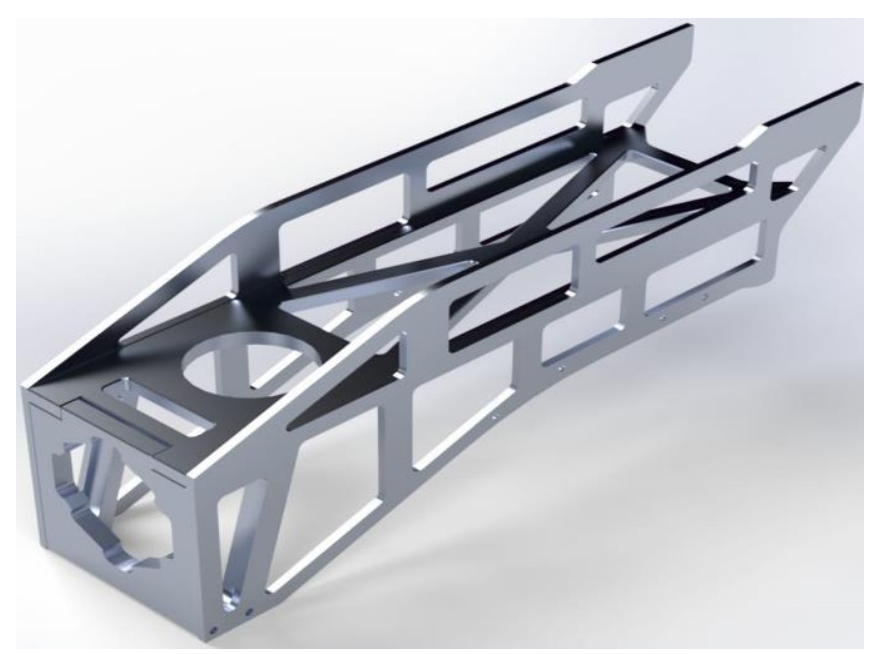

Fig. 2. 3-D model of the chassis.

Another issue is that this project lacks sufficient funding to cover the cost of machining an entirely new chassis. With these two main obstacles in the way, finding a creative and efficient design was critical. The suspension components were designed using the Solidworks CAD tool, then fabricated by $\mathrm{CNC}$ machining and 3D printing. Fig. 3 shows the $3 \mathrm{D}$ rendering of these auxiliary components. Here, Fig. 3(a) is the servo horn extension, Fig. 3(b) is the suspension link and Fig. 3(c) is the suspension link joint or bracket.

To minimize the cost of manufacturing, we decided to manufacture the suspension components from aluminum sheet metal and 3D printed plastic. Table I shows the material with which we fabricated each component. In addition, some of these components are interchangeable. For instance, the suspension links for the front and the rear are identical to e a ch other. The suspension link joints were also designed into two identical parts instead of four. The drilling of extra holes into components and their mirror replicas made their interchangeability possible, such that one screw hole is for the front suspension and the other for the rear. This significantly reduced the manufacturing cost. However, the interchangeability of these parts caused the front and rear suspensions to have different dynamics due to the asymmetry of the body.

TABLE I: SUSPENSION COMPONENTS, MATERIAL, AND FABRICATION TECHNIQUE

\begin{tabular}{|c|c|c|}
\hline Component & Material & $\begin{array}{c}\text { Fabrication } \\
\text { Technique }\end{array}$ \\
\hline $\begin{array}{l}\text { Servo Horn } \\
\text { Extension }\end{array}$ & ABS Plastic & 3D Printing \\
\hline $\begin{array}{l}\text { Suspension } \\
\text { Link }\end{array}$ & $\begin{array}{c}\text { Aluminum EN AW- } \\
\text { 5083/3.3547/AL- } \\
\mathrm{Mg} 4.5 \mathrm{Mn}\end{array}$ & $\begin{array}{c}\text { CNC } \\
\text { Machining }\end{array}$ \\
\hline $\begin{array}{c}\text { Suspension } \\
\text { Link }\end{array}$ & $\begin{array}{c}\text { Aluminum EN AW- } \\
\text { 5083/3.3547/AL- } \\
\text { Mg4.5Mn }\end{array}$ & $\begin{array}{c}\text { CNC } \\
\text { Machining }\end{array}$ \\
\hline
\end{tabular}




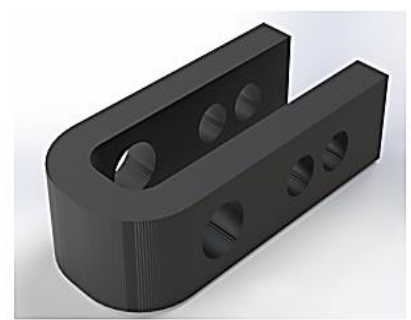

(a) Servo Horn Extension

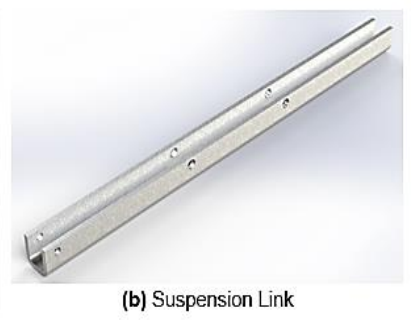

(b) Suspension Link

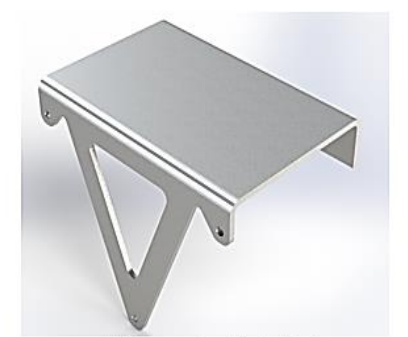

(c) Suspension Link Joint

Fig. 3. Auxiliary Chassis Components.

\section{B. Kinematics: Suspension Mechanism}

Based on the dynamics of the system and the consequent control requirements, the robot's suspension system has four rotary servomotors, making it an active suspension. Also, the presence of four shock absorbers in the suspension system reduces mechanical stress. These dampen sudden impacts during the operation of the system and compensate for fabrication errors in the dimensions of the movable links. To accommodate these requirements, a modified swing axle suspension was developed. This swing axle design has the axle in parallel with the chassis instead of the classical perpendicular design. The suspension is a quadrupedal mechanism, which comprises four parallel 4-bar mechanisms. The notations a, b, c, and d as shown in Fig. 4, denote the four bars of each suspension assembly. These were used in the analysis of the four-bar mechanism. Table II describes each of the denoted link.

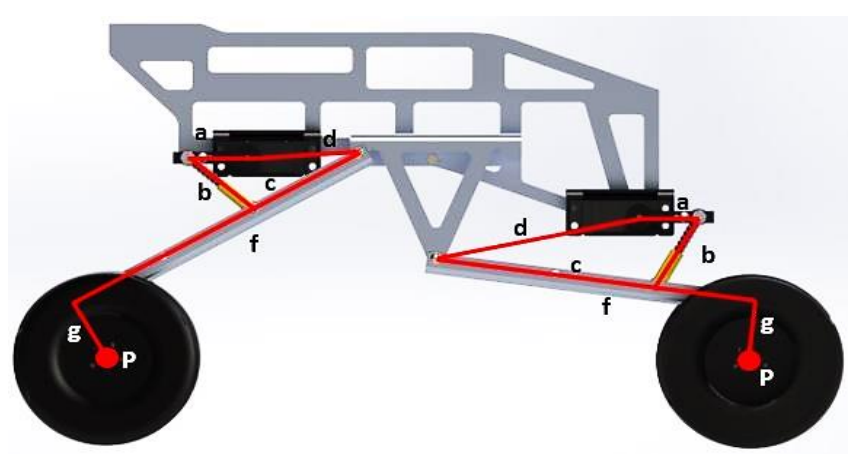

Fig. 4. 2-D Model of the Suspension System.

TABLE II: DESCRIPTION OF THE LINKS AS PARTS OF THE 4-BAR MECHANISM

\begin{tabular}{cc}
\hline Links & Length Description \\
\hline $\mathrm{a}$ & Servo arm \\
$\mathrm{b}$ & Shock absorber \\
$\mathrm{c}$ & Distance between Link Joint and Shock Absorber \\
$\mathrm{d}$ & Distance between Servo and Link Joint \\
$\mathrm{f}$ & Suspension Link \\
$\mathrm{g}$ & Distance between Link and center of the wheel \\
$\mathrm{p}$ & Center of the wheel \\
\hline
\end{tabular}

Having the suspension system behave as parallel four-bar mechanisms provide mathematical relationships that enhance the computation of the ground clearance by the controller. These relationships are equations that relate the angular displacement of bar-a (i.e. the servo arm) and the ground clearance of the robot. Attached to the end of each suspension assembly is a geared-motor (point P), which serves as the endeffector that allows the robot to translate as a hybrid quadrupedal-wheeled mobile system. To minimize the sprung mass, the wheels were directly coupled to the geared- motors. Table III shows the simulated weight (i.e. sprung- and unsprung-weight) of the robots' mechanical components.

TABLE III: SUSPENSION COMPONENTS, MATERIAL, AND FABRICATION TECHNIQUE

\begin{tabular}{ccc}
\hline $\begin{array}{c}\text { Total Mass } \\
(\mathrm{kg})\end{array}$ & $\begin{array}{c}\text { Sprung Mass } \\
(\mathrm{kg})\end{array}$ & Unsprung Mass $(\mathrm{kg})$ \\
\hline 3777.95 & 895.51 & 2882.44 \\
\hline
\end{tabular}

With a relatively lower sprung mass, the suspension can function more efficiently. This reduces the stress on the servomotors and the shock absorbers. Additionally, this helps to prevent damages to the servomotors since their primary function is to lift or rotate the sprung mass of the robot. The resultant weight on the suspension system was also minimized to improve the stiffness of the shock-absorber elements. A stiff suspension is critical because it allows the four-bar mechanism to function properly. Having a soft shock absorber will not properly transfer the forces of the servomotor onto the suspension link. This would affect how accurately the robot can perform the transformations of the suspension links, for gyro-stability and ground clearance. Each of the adopted shock absorbers can suspend a weight of approximately 12 Newtons (i.e. 1200 g) which gives the suspension system the stiffness to counterbalance a cumulative weight of 48 Newtons (i.e. 4800 g). This creates sufficient allowance for carrying other subcomponents like the batteries, sensors, and controller.

In the design of the active suspension system, it was ensured that the front and rear wheels are as close as possible in height, for every angular positioning of the servomotor. This means that if the front and rear servomotors are in the same position, the front and rear wheels should be close to the same height. The controller controls this transformation. This is important as it helps keep the robot leveled when driving on flat terrain and simplifies the control algorithm for the suspension system. This would cause some issues in the design since the chassis significantly restrict the suspension. It is also important to note that the servomotors can only move from $0^{\circ}$ to $180^{\circ}$. To obtain the proper dynamics, we used an iterative approach. This enabled us to compute the ground clearance of the robot for every servo angle. We used Solidworks to perform motion analysis and the S-Math tool to calculate the ground clearance. This approach also enables us to know the change in the servo angle required for reaching the desired values of ground clearance. Table IV lists the restrictions and production specifications for every component in the robot's mechanical system design. For possible design changes, an iterative method is also included for varying the properties of each mechanical component in the system. These constraints made achieving identical 
ground clearance values impossible. We were only able to find approximately equal values. Table $\mathrm{V}$ shows the ground clearance of the front and rear at servo motor angles of $0^{\circ}$, $90^{\circ}$, and $180^{\circ}$.

TABLE IV: LIST OF MANUFACTURED COMPONENTS AND THEIR RESTRICTIONS

\begin{tabular}{ccc}
\hline Part & Restrictions & $\begin{array}{c}\text { Manufactured } \\
\text { (Yes/No) }\end{array}$ \\
\hline Servo-motor & $\begin{array}{c}\text { Location on chassis due to } \\
\text { predrill holes and pre-made servo } \\
\text { bracket } \\
\text { Link Joint }\end{array}$ & No \\
Link & $\begin{array}{c}\text { Left and rion chassis due to } \\
\text { predrill holes } \\
\text { interchangeable }\end{array}$ & Yes \\
$\begin{array}{c}\text { Shock- } \\
\text { absorber }\end{array}$ & Nil & Yes \\
$\begin{array}{c}\text { Servo Horn } \\
\text { Extension }\end{array}$ & $\begin{array}{c}\text { Front and rear need to be } \\
\text { interchangeable }\end{array}$ & No \\
\hline
\end{tabular}

As shown in Table $\mathrm{V}$, the ground clearances are very similar at the extremes and have a maximum difference of only $6.2155 \mathrm{~mm}$. Therefore, we concluded that it is better to have the front ground clearance smaller at $0^{\circ}$ and greater at $180^{\circ}$ since this enhances greater adjustability for climbing or descending a hilly terrain. Fig. 5 shows the side views of the robot at $0^{\circ}, 90^{\circ}$, and $180^{\circ}$ servo-suspension levels (See Appendix for the 3D version of Fig. 5)

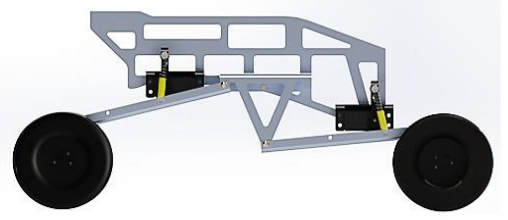

(a) Robot with servomotors at $0^{\circ}$

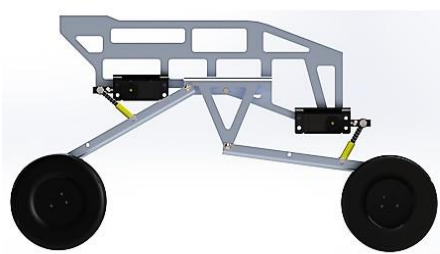

(b)Robot with servomotors at 90

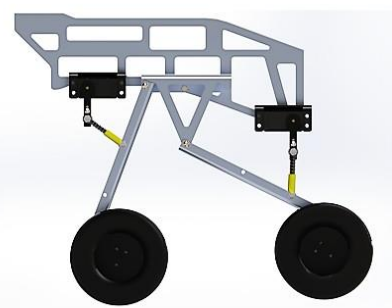

(c) Robot with servomotors at $180^{\circ}$
Fig. 5. 2-D Model of the Suspension System.

\begin{tabular}{ccc}
\multicolumn{2}{c}{ TABLE V: FRONT AND REAR GROUND CLEARANCE PER SERVO ANGLE } \\
\hline $\begin{array}{c}\text { Servo Motor } \\
\text { Angle }\left({ }^{\circ}\right)\end{array}$ & $\begin{array}{c}\text { Front Ground Clearance } \\
(\mathrm{mm})\end{array}$ & $\begin{array}{c}\text { Rear Ground } \\
\text { Clearance }(\mathrm{mm})\end{array}$ \\
\hline 0 & 66.7539 & 69.1072 \\
90 & 107.0085 & 108.8008 \\
180 & 166.6552 & 160.4397 \\
\hline
\end{tabular}

\section{Dynamics: Tip-over Stability}

A major purpose for our quadrupedal-wheel drive mechanism is to enhance tip-over stability by gyrostabilization while it navigates on rough topographies, as described in Fig. 6. This is to ensure the dynamic stability of our robot - restoration of the roll- and pitch- angle to equilibrium with respect to the gravitational line of action as shown in Fig. 6 Based on the work of (2), we used Fig. 7 to derive a mathematical model for the tip-over stability of our robotic system.

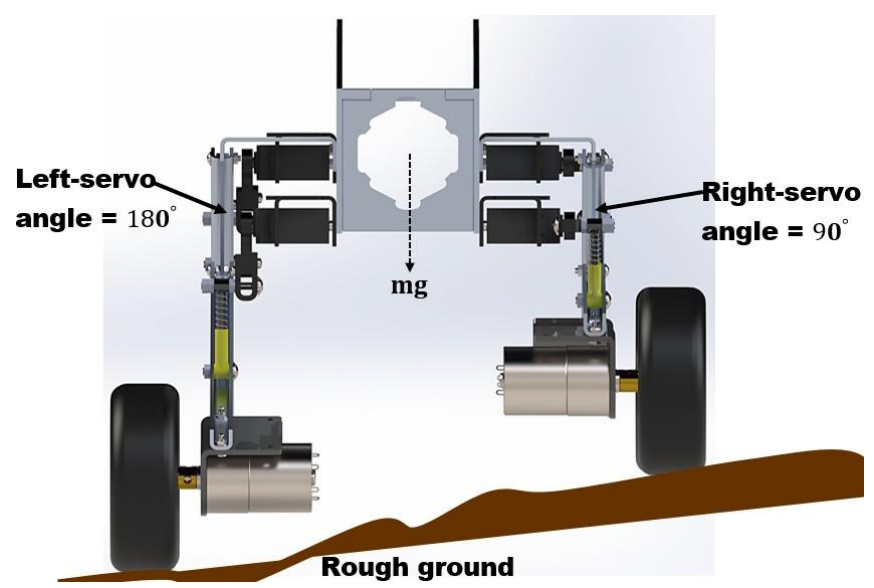

Fig. 6. Description of gyro-stabilized quadrupedal driving.

Considering the model in Fig. 7(a), the robot has L number of joints, denoted by the variable $\theta_{j}$, where $j=\{1, \ldots, L\}$. Assuming that the wheels are in contact with the ground, the variable $P_{k}, k=\{1, \ldots, n\}$ denotes the $\mathrm{n}$ wheel-ground contact points, with $\overrightarrow{\boldsymbol{P}}_{\boldsymbol{k}}, k=\{1, \ldots, n\}$ as a vector that defines their location from the centre of mass, $c$ of the robotic system. The variable $\alpha_{k}, k=\{1, \ldots, n\}$ denotes the wheel-ground contact angles at point $P_{k}$. These angles are measured with respect to the horizontal axis. The lines joining the points $P_{k}$ are the tip-over axes and denoted by $\overrightarrow{\boldsymbol{t}}_{i}, i=\{1, \ldots, n-1\}$, as shown in Fig. 7(b). The $i^{\text {th }}$ tip-over axis is expressed in Eq.1 and Eq. 2 as:

$\overrightarrow{\boldsymbol{t}}_{i}=\overrightarrow{\boldsymbol{P}}_{\boldsymbol{i}+\mathbf{1}}-\overrightarrow{\boldsymbol{P}}_{\boldsymbol{i}}$

$\overrightarrow{\boldsymbol{t}}_{n}=\overrightarrow{\boldsymbol{P}}_{\mathbf{1}}-\overrightarrow{\boldsymbol{P}}_{n}$

According to [2] and [10], a WMR with $n$ legs or wheels in contact with the ground has $n$ numbers of tip-over axes, of which normal $\overrightarrow{\boldsymbol{I}}_{i}$ intersects with the center of mass as described in Eq. 3 as"

$\overrightarrow{\boldsymbol{I}}_{i}=\left(1-\hat{\boldsymbol{t}}_{i} \hat{\boldsymbol{t}}_{i}^{T}\right) \overrightarrow{\boldsymbol{P}}_{\boldsymbol{i + 1}}$

The variable $\hat{\boldsymbol{t}}=\boldsymbol{t} / \operatorname{det}(\boldsymbol{t})$. We calculated the stability angles for each tip-over axis as the angle between the line of action of the robot's weight $m \overrightarrow{\boldsymbol{g}}$ and the axis normal $\overrightarrow{\boldsymbol{I}}_{i}$ as given in Eq. 4 as

$\delta_{i}=\sigma_{i} \cos ^{-1}\left(m \overrightarrow{\boldsymbol{g}} \cdot \overrightarrow{\boldsymbol{I}}_{i}\right)$,

where $i=\{1, \ldots, n\}$ and

$\sigma_{i}=\left\{\begin{array}{l}+1 \text { for }\left(\overrightarrow{\boldsymbol{I}}_{i} \times m \overrightarrow{\boldsymbol{g}}\right) \cdot \overrightarrow{\boldsymbol{t}}_{\boldsymbol{i}}<0 \\ -1 \text { for }\left(\overrightarrow{\boldsymbol{I}}_{i} \times m \overrightarrow{\boldsymbol{g}}\right) \cdot \overrightarrow{\boldsymbol{t}}_{\boldsymbol{i}} \geq 0\end{array}\right.$

The expression in Eq. 6 defines the overall stability angle of our robot, as the minimal of the $\mathrm{n}$ stability angles.

$\beta=\min \left(\delta_{i}\right), i=\{1, \ldots, n\}$

The robot will tip-over whenever the condition $\beta<0$ is 
true. The values of $\theta_{j}$, as shown in Fig. 7 (a), is varied by the suspension servomotors to influence the wheel-ground contact angle $\alpha_{k}$, based on measurements from the inertial sensor. Our current objective is to provide a model for a controller that maintains a large value of $\beta$ so that the robot can navigate on rough topographies without tipping over. More analysis on this will continue in the next phase of our project. This accounts for the values of $\theta_{j}$ and other unbalanced forces in our robotic system, such as manipulation forces for repositioning instruments. Also, one element of our design that enhances the tip-over stability is a low center of gravity. We lowered the center of gravity of our robot by having a larger proportion of its mass at the wheels. Coupled with the usage of a programmable controller, this essentially enhances the tip-over stability of our robotic system.

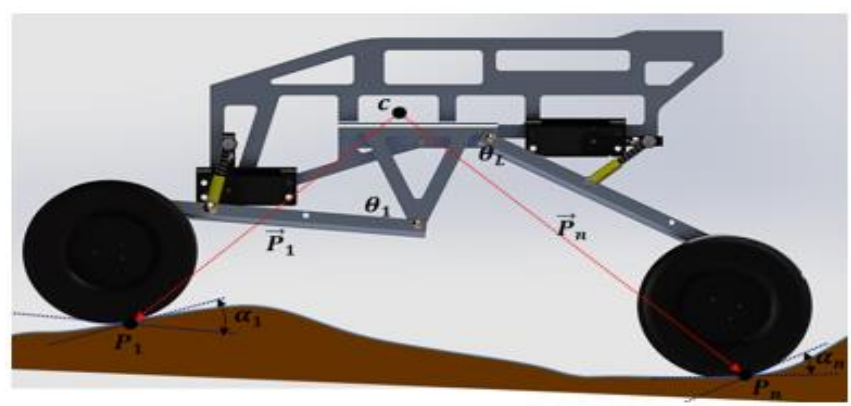

(a) 2D Description of Quadrupedal Driving on Rough Ground

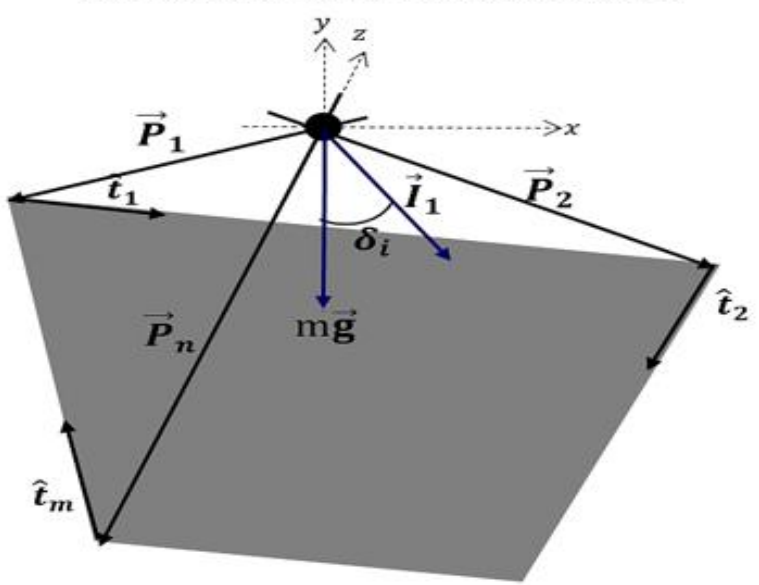

(b) Geometrical Model for Stability Analysis

Fig. 7. Model of Tip-over Stability Analysis.

\section{Skid-steering Dynamic Model}

We designed our robotic system to maneuver and change path by means of the skid steering, which is more of a dynamic model and less of mechanical design. To enable this skid steering, the kinematic dimensions of the robot must be equal. We achieved this by mechanically transforming the suspension system to a level that corresponds to a servo angle of $180^{\circ}$ This effectively transforms the rectangular planar shape of the robot to a square - such that the centers of the wheels are equidistant from one another as shown in Fig.8. Based on Fig. 8 and the relevant theories [8], [11], [12], we derived dynamic equations to describe the 2-DoF planar motion of our robot.

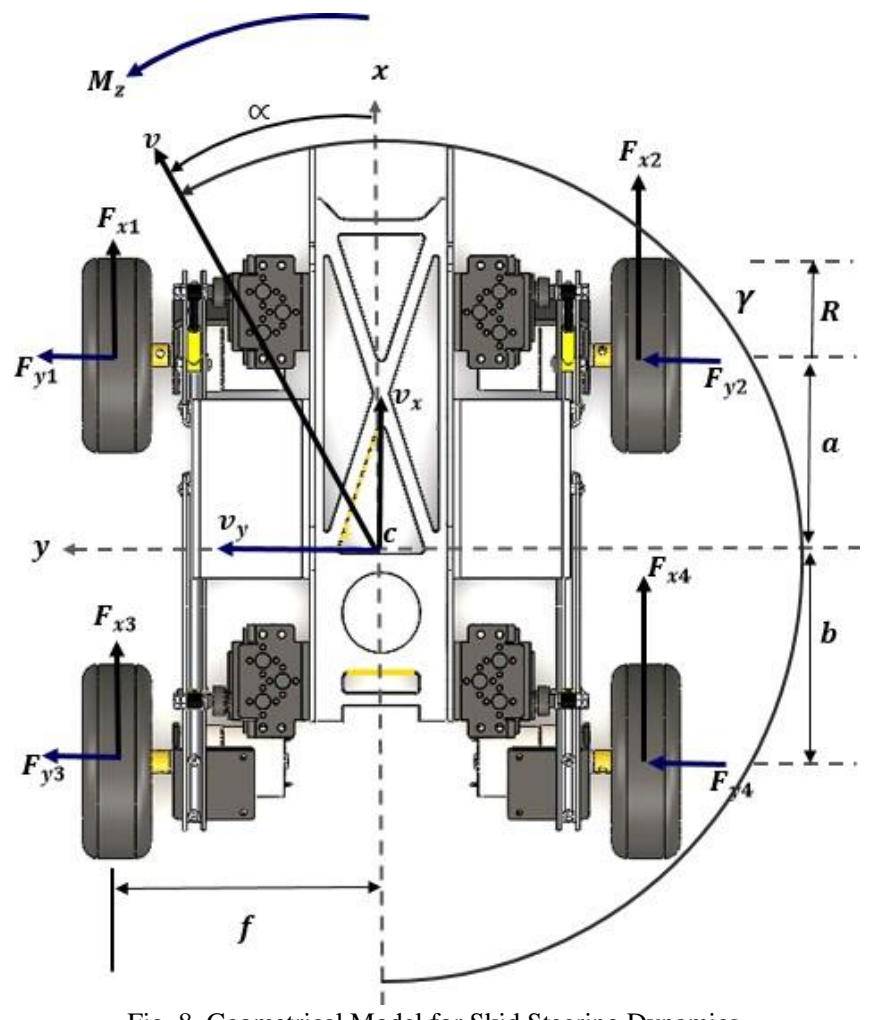

Fig. 8. Geometrical Model for Skid Steering Dynamics.

The lateral and yaw motion of our robot is modeled in Eq. 7 and Eq. 8 respectively as:

$$
\begin{aligned}
& m \boldsymbol{v}(\dot{\propto}+\gamma)=\left(\boldsymbol{F}_{y 1}+\boldsymbol{F}_{y 2}\right)+\left(\boldsymbol{F}_{y 3}+\boldsymbol{F}_{y 4}\right)=\boldsymbol{F}_{y f}+\boldsymbol{F}_{y r} \\
& I_{z} \dot{\gamma}=M_{z}+a \boldsymbol{F}_{y f}-b \boldsymbol{F}_{y r} .
\end{aligned}
$$

The variables $M_{z}, \boldsymbol{F}_{y f}$ and $\boldsymbol{F}_{y r}$ are given as

$$
\begin{aligned}
& M_{z}=f \frac{\Delta \tau}{R}, \\
& \boldsymbol{F}_{y f}=-2 K_{f}\left(\propto+\frac{a}{v} \gamma\right), \\
& \boldsymbol{F}_{y r}=-2 K_{r}\left(\propto-\frac{b}{v} \gamma\right) .
\end{aligned}
$$

We substituted Eqs. 10 and 11 into Eqs. 7 and 8 to derive:

$m v \dot{\alpha}+2\left(K_{f}+K_{r}\right) \dot{\alpha}+\left[m v+\frac{2}{v}\left(a K_{f}-b K_{r}\right)\right] \gamma=0$

$2\left(a K_{f}-b K_{r}\right) \propto+I_{z} \dot{\gamma}+2 \frac{\gamma}{v}\left(a^{2} K_{f}+b^{2} K_{r}\right)=M_{z}$.

In matrix form, we combined Eqs. 12 and 13 as,

$$
\begin{aligned}
& {\left[\begin{array}{cc}
m \boldsymbol{v} s+2\left(K_{f}+K_{r}\right) & m \boldsymbol{v}+\frac{2}{v}\left(a K_{f}-b K_{r}\right) \\
2\left(a K_{f}-b K_{r}\right) & I_{z} s+\frac{2}{v}\left(a^{2} K_{f}+b^{2} K_{r}\right)
\end{array}\right]\left[\begin{array}{c}
\propto(s) \\
\gamma(s)
\end{array}\right]=} \\
& {\left[\begin{array}{c}
0 \\
M_{z}
\end{array}\right] .}
\end{aligned}
$$

From Eq. 14, we derived the equation for computing the stead-state yaw rate response of the robot as: 
$Y_{S S}=\left(\frac{1}{1-m \frac{v^{2}}{2(a+b)^{2} \frac{\left(a K_{f}-b K_{r}\right)}{K_{f} K_{r}}}}\right) \frac{v\left(K_{f}+K_{r}\right)}{2 K_{f} K_{r}(a+b)^{2}} M_{z}$,

According to [8], the steady-state yaw response equivalence in the Ackermann steering system is given in Eq. 16.

$Y_{S S}=\left(\frac{1}{1-m \frac{v^{2}}{2(a+b)^{2} \frac{\left(a K_{f}-b K_{r}\right)}{K_{f} K_{r}}}}\right) \frac{v \psi}{(a+b) r}$.

By comparing Eqs. 15 and 16, we derived:

$M_{z}=\frac{2 K_{f} K_{r}(a+b) \psi}{\left(K_{f}+K_{r}\right) r}$

The variable $M_{z}$ is used to compute the resultant yaw moment of the skid-steering robot. To calculate the steering torque, $\Delta \tau$ of the robot, we compared Eqs. 17 and 9 to derived

$\Delta \tau=\frac{2 K_{f} K_{r}(a+b) \psi R}{\left(K_{f}+K_{r}\right) f r}$

The variable $\Delta \tau$ is differential driving torque between the two sides of the front wheels. It is expressed as:

$\Delta \tau=T_{f 1}-T_{f 2}=\left(F_{x 1}-F_{x 2}\right) R$

In Eq. 19 , the variable $T_{f 1}$ is the driving torque produced by the left wheel, while $T_{f 2}$ is that produced by the right wheel. Based on rotational dynamics, $\Delta \tau$ is proportional to the radius of the driving wheels. The distance $a=b \approx f$, whenever all the suspension servomotors rotates to angle $180^{\circ}$. To this effect, Eq. 18 becomes Eq. 20, which minimizes the size of differential driving torque required to steer the robot, given as:

$\Delta \tau \approx \frac{4 K_{f} K_{r} \psi R}{\left(K_{f}+K_{r}\right) r}$

Table VI gives the full list of variables for the skid steering analysis. This analysis is for developing the skid steering controller of our robotic system.

TABLE VI: VARIABLES FOR SKID-STEERING ANALYSIS AND THEIR MEANING

\begin{tabular}{|c|c|}
\hline \multicolumn{2}{|r|}{ MEANING } \\
\hline Variable & Meaning \\
\hline$A$ & $\begin{array}{l}\text { Distance from the mass center of the robot to the front } \\
\text { axle }\end{array}$ \\
\hline$B$ & $\begin{array}{l}\text { Distance from the mass center of the robot to the real } \\
\text { axle }\end{array}$ \\
\hline$F$ & Half the wheel track \\
\hline$F_{x 1}$ & Tractive-force of the front-left wheel \\
\hline$F_{x 2}$ & Tractive-force of the front-right wheel \\
\hline$F_{x 3}$ & Tractive-force of the rear-left wheel \\
\hline$F_{x 4}$ & Tractive-force of the rear-right wheel \\
\hline $\boldsymbol{F}_{y f}$ & Linear lateral force produced by front wheels \\
\hline $\boldsymbol{F}_{y r}$ & Linear lateral force produced by rear wheel \\
\hline
\end{tabular}

\begin{tabular}{cc}
\hline $\boldsymbol{F}_{y 1}$ & Linear lateral force produced by front-left wheel \\
$\boldsymbol{F}_{y 2}$ & Linear lateral force produced by front-right wheel \\
$\boldsymbol{F}_{y 3}$ & Linear lateral force produced by rear-left wheel \\
$\boldsymbol{F}_{y 4}$ & Linear lateral force produced by rear-right wheel \\
$I_{z}$ & Yaw moment of inertia \\
$K_{f}$ & Cornering stiffness of the front wheel \\
$K_{r}$ & Cornering stiffness of the rear wheel \\
$\mathrm{M}$ & Total mass of the robot \\
$M_{z}$ & Gear ratio in 2-wheel steering \\
$\mathrm{R}$ & Driving torque produced by the left wheel \\
$T_{f 1}$ & Driving torque produced by the right wheel \\
$T_{f 2}$ & Steering torque \\
$\Delta \tau$ & Radius of the wheels \\
$R$ & Resultant velocity of the robot \\
$v$ & Side-slip angle of the robot \\
$\propto$ & Yaw rate of the robot \\
$\gamma$ & Driver's steering wheel angle \\
$\Psi$ &
\end{tabular}

\section{Simulations AND ANALYSES}

For clarity of analysis, our FEA simulations and analysis are categorized into two main parts. The analysis of the robot's mechanical stress and that of its ground clearance.

\section{A. Mechanical Stress Analysis}

To verify the structural integrity of our robotic system, we performed an FEA simulation on the auxiliary components. Since these make up the suspension and drive system, it was important to verify that they can withstand the forces they may face during the operation of the robotic system. Fig. $9-$ Fig. 13 shows the results of the analysis. The green arrows represent fixed geometry, whereas purple and black arrows represent the forces. Table VII lists the forces that are applied to the parts as well as the scale used for their deformation. We performed two simulations on the suspension link joint because the complexity of the part made it difficult to assume the directions of the forces. The first simulation has the forces up and away whereas the second has them down and in. We also performed two simulations on the suspension link, as there are two mounting points for the shock absorber. The presence of red coloration on any portion of the structure indicates that the structure is susceptible to mechanical failure at that portion.

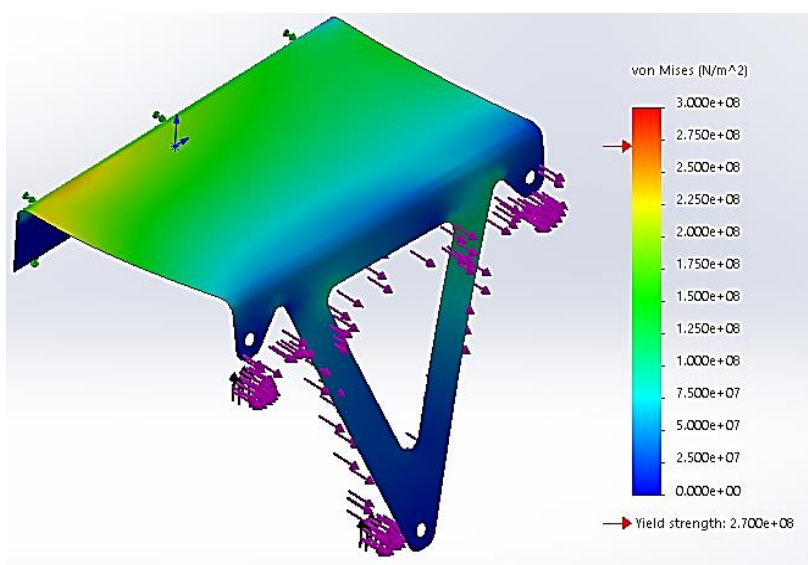

Fig. 9. FEA Simulation of the Suspension Link Joint 1. 


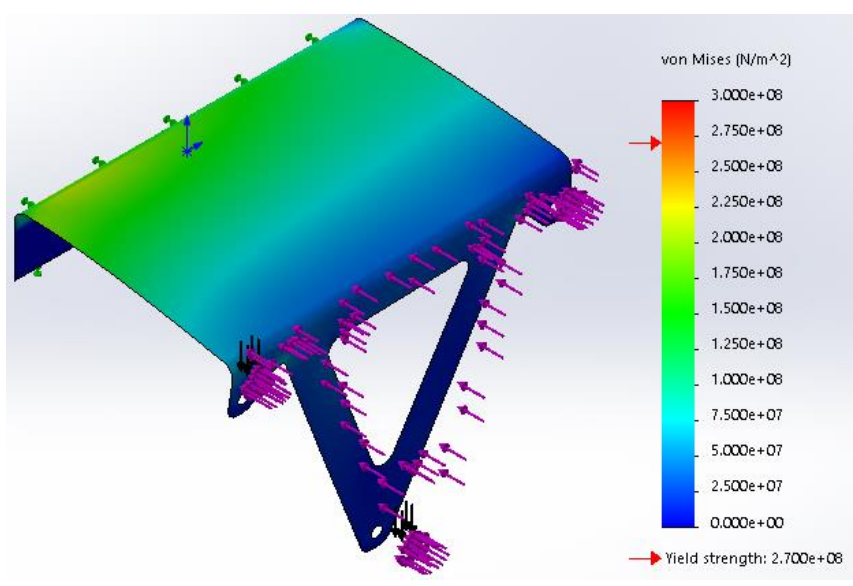

Fig. 10. FEA Simulation of the Suspension Link Joint 2.

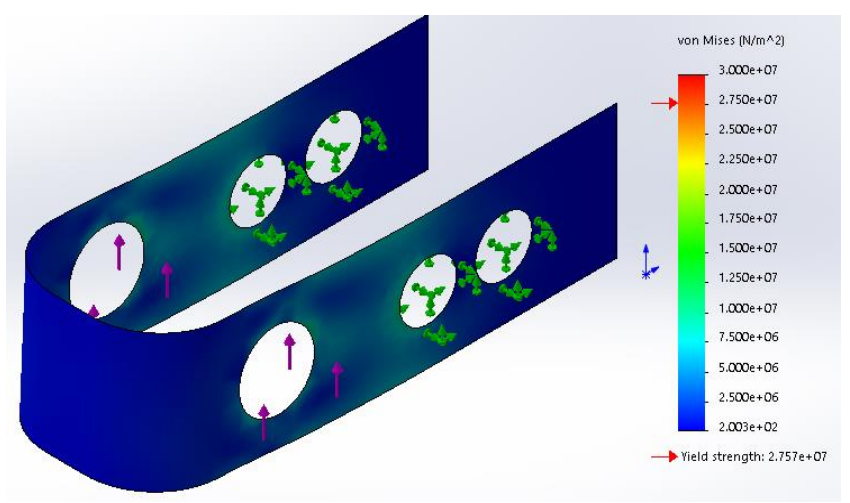

Fig. 11. FEA Simulation of the Servo Horn Extension.

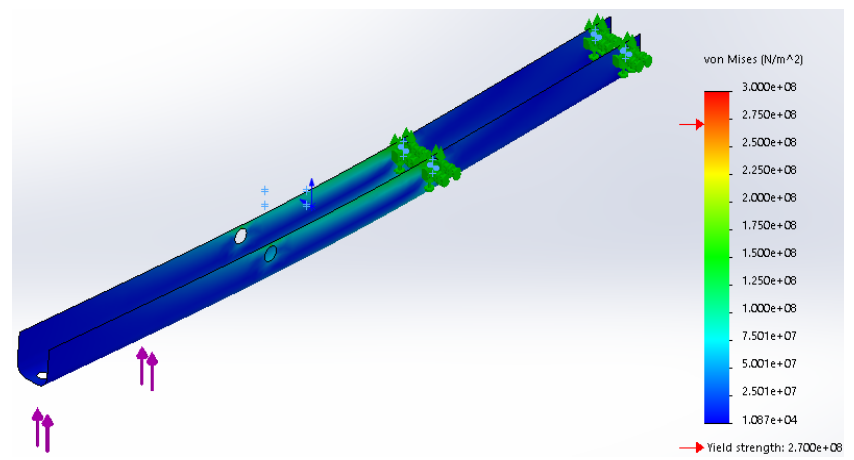

Fig. 12. FEA simulation of the Suspension Link 1.

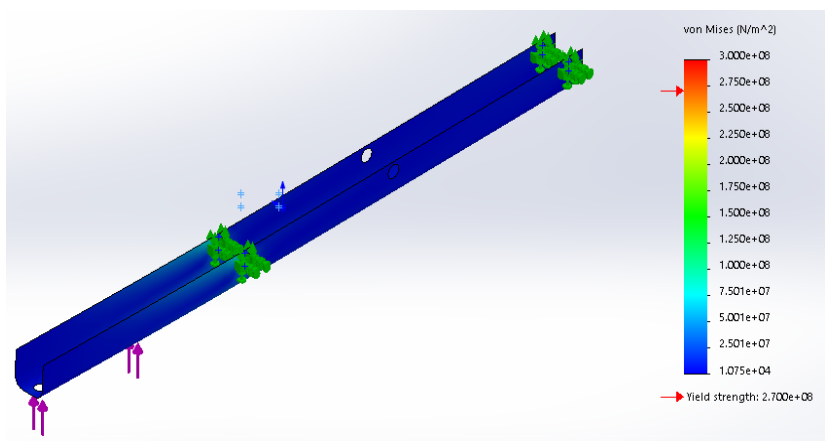

Fig. 13. FEA Simulation of the Suspension Link 2.

The FEA simulations show that the suspension link joints are more susceptible to failure. This is indicated by the presence of more reddish coloration on this part than the other parts, which have lower force values. Logically, this part is prone to fail first as it connects to the two suspension assemblies, thus giving it twice as much force. The two Suspension Link Joint simulations demonstrate that the part is weaker against the upward and lateral forces. Thus, we deduced that the link suspension joint is fully loaded when all the four wheels receive 100 newtons of force. This suggests that our robotic system can carry a payload of approximately 41 kilograms. This is unrealistic as the shock absorbers are made of plastic and will probably fail before reaching 41 kilograms. Since we did not design our robot to carry any payload other than its subcomponents, we infer that our robot is mechanically durable and will not fail in operation.

\begin{tabular}{cccc}
\multicolumn{4}{c}{ TABLE VII: FEA ANALYSIS - COLOR CODE AND SCALE OF DEFORMATION } \\
\hline Component & $\begin{array}{c}\text { Purple Forces } \\
(\mathrm{N})\end{array}$ & $\begin{array}{c}\text { Black } \\
\text { Forces (N) }\end{array}$ & $\begin{array}{c}\text { Scale of } \\
\text { Deformation }\end{array}$ \\
\hline $\begin{array}{c}\text { Suspension Link } \\
\text { Joint 1 }\end{array}$ & 20 & 100 & $2: 1$ \\
$\begin{array}{c}\text { Suspension Link } \\
\text { Joint 2 }\end{array}$ & 20 & 100 & $2: 1$ \\
$\quad \begin{array}{l}\text { Servo Horn } \\
\text { Extension }\end{array}$ & 150 & N/A & $200: 1$ \\
$\begin{array}{c}\text { Suspension Link 1 } \\
\text { Suspension Link 2 }\end{array}$ & 150 & N/A & $5: 1$ \\
\hline
\end{tabular}

\section{B. Ground-clearance Analysis}

A robot with an active suspension requires an analysis of the change in ground clearance throughout every position of the suspension components. This allows for the design of a control algorithm that enables the robot to react proportionately to the topography of its path. This analysis is crucial in the design of the front and rear suspension. Thus, the controller can synchronize the dynamics of the two suspension systems. Since the suspension system is a fourbar mechanism, it is possible to calculate the position of the chassis relative to the ground for every given angle of the servo motor. The bottommost point of the vehicle (with the wheels excluded), is where the rear suspension link connects to the suspension link joint. We used the geometrical description in Fig. 14 to calculate the values of ground clearance in correspondence to each servo-suspension angle. To ensure the accuracy of these values, we compared them with the Solidworks model at the serve angles $0^{\circ}, 90^{\circ}$ and $180^{\circ}$. Table VIII shows the results of this comparison.

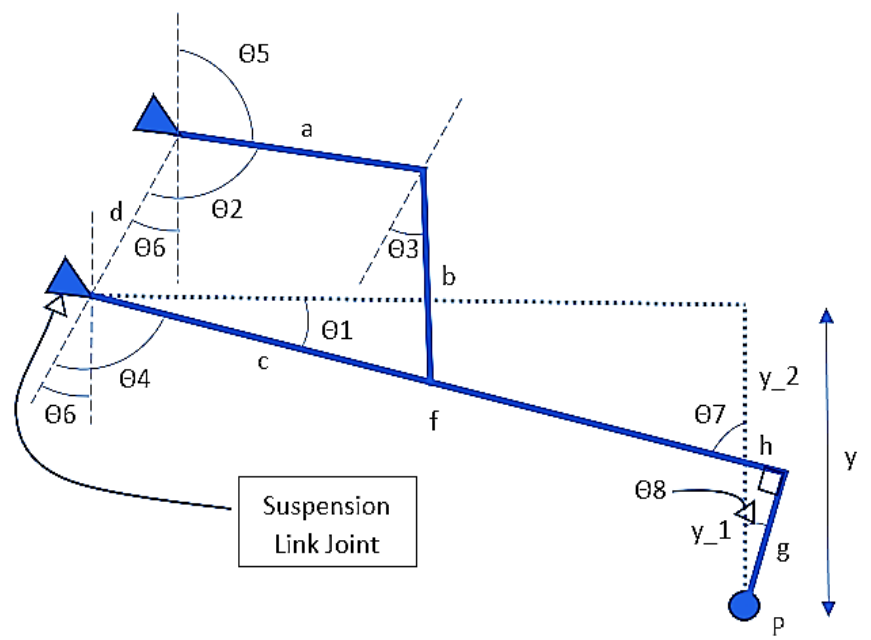

Fig. 14. Geometry of the suspension as a four-bar mechanism. 
TABLE VIII: COMPARING THE CALCULATED AND CAD-DERIVED VALUES OF GROUND-CLEARANCE PER SERVO ANGLE

\begin{tabular}{rcccc}
\hline \multirow{2}{*}{$\begin{array}{r}\text { Servo } \\
\text { Angle }\left({ }^{\circ}\right)\end{array}$} & \multicolumn{2}{c}{$\begin{array}{c}\text { Calculated Ground- } \\
\text { clearance }(\mathrm{mm})\end{array}$} & \multicolumn{2}{c}{$\begin{array}{r}\text { CAD-derived Ground- } \\
\text { clearance }(\mathrm{mm})\end{array}$} \\
\cline { 2 - 5 } & Front & Rear & Front & Rear \\
\hline 0 & 66.7539 & 69.1072 & 66.7500 & 69.1100 \\
90 & 107.0085 & 108.8008 & 107.0000 & 108.800 \\
180 & 166.6552 & 160.4397 & 166.6500 & 160.4400 \\
\hline
\end{tabular}

Since the values at these three angles are approximately equal, we concluded that our calculation is accurate. With the $\mathrm{S}$-Math calculator setup, it is then possible to calculate the ground clearance of the robot for every servo angle. To accomplish this, we varied the servo angle $\theta 5$ in Fig. 14, and computed the corresponding value of ground-clearance. We adopted the calculator setup for two main purposes. Firstly, we used it for the design and iterative synchronization of the front and rear suspension. Secondly, it was used to document the ground clearance computation for every servo angle at one-degree increments. The accrued data were plotted in graphs. For each suspension system, two graphs were plotted - one for ground clearance vs servo angle and the other for servo angle vs ground clearance. Also, we generated a $6^{\text {th }}$ degree polynomial trendline for each graph, which we used to determine the accuracy of the equations for the data fitting. We will use these equations to design a control algorithm for the ground-clearance, in the next phase of this project. Fig.15 to Fig. 18 is the graphical summary of our ground-clearance analysis.

The trendline equations are complex because they are sixth-degree polynomials with ten decimal points. However, this is to ensure numerical accuracy. Since these equations will be encoded into the controller, its accuracy is more important than its simplicity, as proven by the $\mathrm{R}^{2}$ values the ground-clearance linear curve-fitting analysis. Table IX shows the values of these R-squared values per graph.

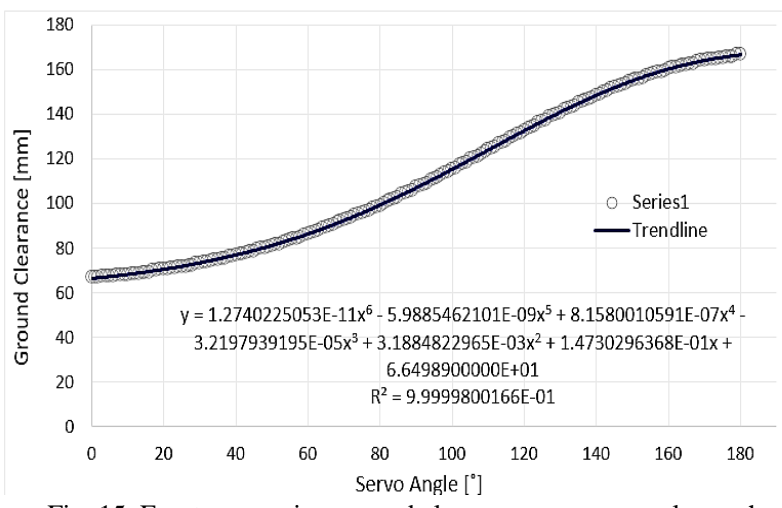

Fig. 15. Front suspension ground clearance vs servo angle graph.

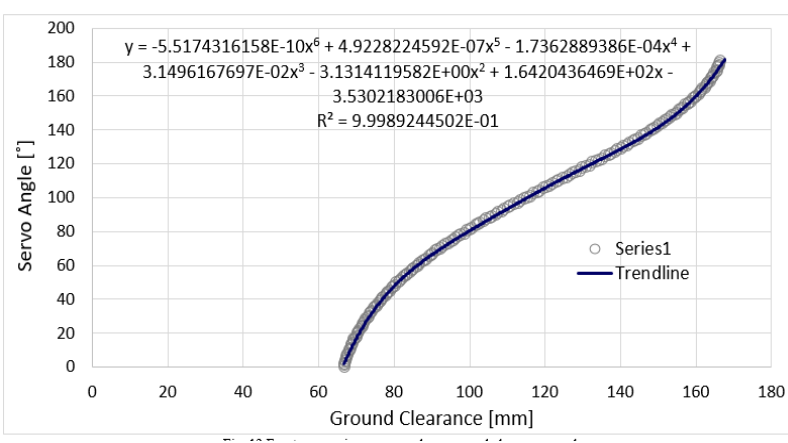

Fig. 16 Front suspension servo angle vs ground clearance graph.

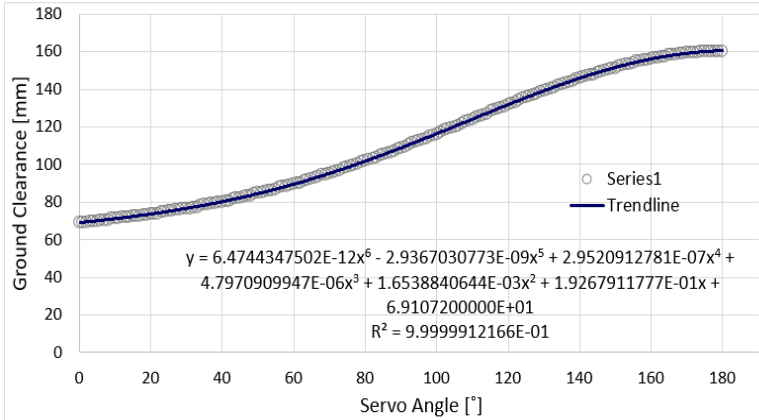

Fig. 17 Rear suspension ground clearance vs servo angle graph.

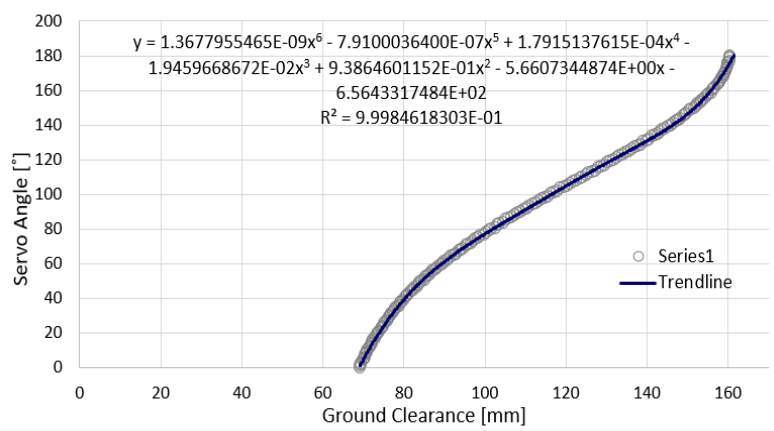

Fig. 18 Rear suspension-servo angle vs ground clearance graph.

TABLE IX: R-SQUARED VALUES PER GRAPH OF THE GROUND-CLEARANCE ANALYSIS

\begin{tabular}{ccccc}
\hline & \multicolumn{3}{c}{$\begin{array}{c}\text { Ground Clearance vs } \\
\text { Servo Angle }\end{array}$} & \multicolumn{2}{c}{$\begin{array}{c}\text { Servo Angle vs Ground } \\
\text { Clearance }\end{array}$} \\
\cline { 2 - 5 } & Front & Rear & Front & Rear \\
\hline $\begin{array}{c}\mathrm{R}^{2} \\
\text { value }\end{array}$ & 0.99999 & 0.9999991 & 0.99989244 & 0.9998461 \\
\hline
\end{tabular}

The $\mathrm{R}^{2}$ values indicate that the trendline equations are accurate. Although the difference is small, it is important to note that the Servo Angle vs Ground Clearance values are slightly less accurate. This is because it has no y-intercept. Since the Ground Clearance vs Servo Angle graphs have an intercept, it is possible to set the intercept at the desired value. With the S-Math calculator, it is possible to predetermine the ground clearance for the servo angle of zero. For this reason, it is better to use the Ground Clearance vs Servo Angle equations for the controller design.

\section{Physical Implementation}

Based on the design in Fig. 3 and materials specifications in Table I, the auxiliary components of the robot's mechanical sub-system is fabricated. Coupled with further development of the electrical sub-system and the controller, which is currently in progress, the robotic system that is described in this paper is realized. Fig. 19 depicts the complete structure of this robotic system. 


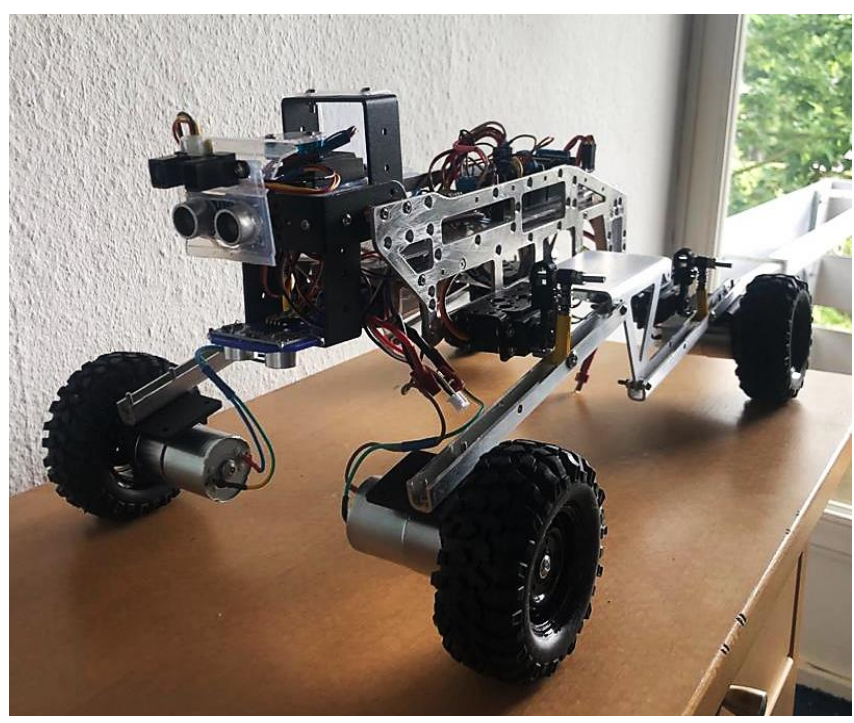

Fig. 19. The Quadrupedal-wheeled Robot in its finished Form.

\section{CONCLUSION}

In this paper, a mechanical design of an active-suspension quadrupedal-wheel robot is proposed. This involved some manufacturing techniques and analytical models for controller development. They include models for the control of ground clearance, tip-over stability, and skid steering. To determine the durability of the mechanical parts with respect to the dynamic models, FEA simulations were performed. These indicate that our robot is mechanically durable and will not fail in operation, as long as it functions within its dynamical constraints. Also, the $\mathrm{R}^{2}$ values indicate that the trendline equations are accurate, irrespective of some minor discrepancies. The next phase of our work will incorporate the developed prototype, its control electronic and embedded software. The dynamic models in this paper will be used to develop the relevant controller algorithms for the robotic system.

\section{APPENDIX}

The 3D Description of the Standard Servo-suspension Levels.

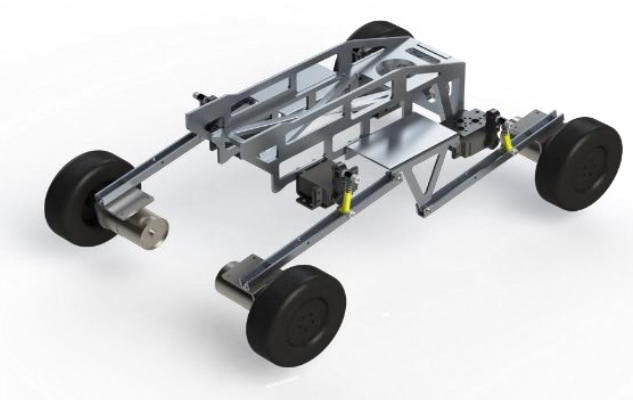

Fig. A1 Suspension servo angle at $0^{\circ}$.

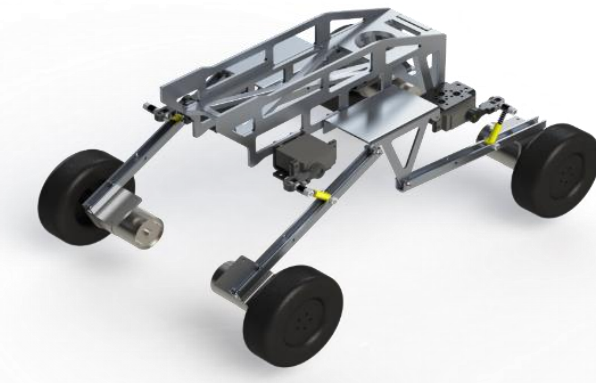

Fig. A2 Suspension servo angle at $90^{\circ}$

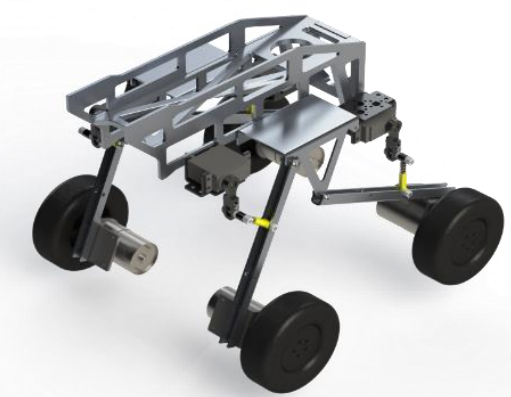

Fig. A3 Suspension servo angle at $180^{\circ}$.

\section{ACKNOWLEDGMENT}

We acknowledge the contributions made by Arvin Instruments Nigeria Limited, as part of its mission to advance industrial and educational technology in Africa and beyond. We also acknowledge the contributions of our research associates from the University of Alberta, Canada.

\section{REFERENCES}

[1] Y.Sun, Y. Yang, S. Ma, and H. Pu, "Design of a high- mobility multiterrain robot based on eccentric paddle mechanism," Robotics and Biomimetics, vol. 3(8), pp. 1-11, 2016.

[2] K. Iagnemma, A. Rzepniewski, and S. e. a. Dubowsky, "Control of robotic vehicles with actively articulated sus- pensions in rough terrain," Autonomous Robots, vol. 14, pp. 5-16, 2003.

[3] K. Kozlowski and D. Pazderski, "Modeling and control of a 4-wheel skid-steering mobile robot," Intl. Journal of Applied Mathematics and Computational Science, vol. 14(4), pp. 477-496, 2004.

[4] A. Gonzalez, E. Ottaviano, and M. Ceccarelli, "On the kinematic functionality of a four-bar based mechanism for guiding wheels in climbing steps and obstacles," Mechanism and Machine Theory, vol. 44(8), pp. 1507-1523, 2009.

[5] E. Ottaviano and P. Rea, "Design and operation of a 2- dof leg-wheel hybrid robot," Robotica, vol. 31(8), pp. 1319-1325, 2013.

[6] S. Hirose and H. Takeuchi, "Study on roller-walk (basic characteristics and its control)," Proceedings of IEEE International Conference on Robotics and Automation, Minneapolis, MN, USA, vol. 4, pp. 3265 3270, 1996.

[7] O. Olakanmi and M. Benyeogor, "Internet based tele- autonomous vehicle system with beyond line-of-sight capability for remote sensing and monitoring," Internet of Things, vol. 5, pp. 97-115, 2019.

[8] O. Mokhiamar and S. Amine, "Lateral motion control of skid steering vehicles using full drive-by-wire system," Alexandria Engineering Journal, vol. 56, pp. 383-394, 2017.

[9] H. Jiang, G. Xu, W. Zeng, F. Gao, and K. Chong, "Lateral stability of a mobile robot utilizing an active adjustable suspension," MDPI Applied Sciences, vol. 9(20), p.4410, 2019.

[10] E. Papadopoulos and D. Rey, "A new measure of tip-over stability for mobile manipulator," Proceedings of IEEE International Conference on Robotics and Automation, vol. 4, pp. 3111-3116, 1996.

[11] E. Martínez-García and R. Torres-Córdoba, "4wd skid- steer trajectory control of a rover with spring-based suspension analysis," International 
Conference on Intelligent Robotics and Applications - Third International Conference, ICIRA, vol. 6424, p. 036103, 2010.

[12] J. Tian, J. Tong, and S. Luo, "Differential steering control of four-wheel independent-drive electric vehicles," MDPI Energies, vol. 11(11), pp. $1-18,2018$. 